\title{
Influence of radiation damage on krypton diffusion in silicon carbide
}

\author{
E. Friedland", T.T. Hlatshwayo, N.G. van der Berg, M.C. Mabena \\ ${ }^{a}$ Physics Department, University of Pretoria, Pretoria, South Africa
}

Keywords silicon carbide, diffusion, radiation damage

*Corresponding author. E mail: erich.friedland@ up.ac.za, Phone: +27-12-4202453, Fax: +27-12-3625288

\begin{abstract}
Diffusion of krypton in poly and single crystalline silicon carbide is investigated and compared with the previously obtained results for xenon, which pointed to a different diffusion mechanism than observed for chemically active elements. For this purpose $360 \mathrm{keV}$ krypton ions were implanted in commercial $6 \mathrm{H}-\mathrm{SiC}$ and CVD-SiC wafers at room temperature, $350{ }^{\circ} \mathrm{C}$ and $600{ }^{\circ} \mathrm{C}$. Width broadening of the implantation profiles and krypton retention during isochronal and isothermal annealing up to temperatures of $1400{ }^{\circ} \mathrm{C}$ was determined by RBS-analysis, whilst in the case of $6 \mathrm{H}-\mathrm{SiC}$ damage profiles were simultaneously obtained by $\alpha$ particle channelling. Little diffusion and no krypton loss was detected in the initially amorphized and eventually recrystallized surface layer of cold implanted $6 \mathrm{H}-\mathrm{SiC}$ during annealing up to $1200{ }^{\circ} \mathrm{C}$. Above that temperature thermal etching of the implanted surface became increasingly important. No diffusion or krypton loss is detected in the hot implanted $6 \mathrm{H}-\mathrm{SiC}$ samples during annealing up to $1400{ }^{\circ} \mathrm{C}$. Radiation damage dependent grain boundary diffusion is observed at $1300{ }^{\circ} \mathrm{C}$ in CVD-SiC. The results seem to indicate, that the chemically inert noble gas atoms do not form defect-impurity complexes, which strongly influence the diffusion behaviour of other diffusors in silicon carbide.
\end{abstract}

\section{Introduction}

Modern high-temperature gas-cooled nuclear reactors (HTGR's) commonly use fuel elements containing triple isotropic (TRISO) fuel particles, where four successive layers of low-density pyrolitic carbon, high-density pyrolitic carbon, silicon carbide and high-density pyrolitic carbon surround the fuel kernel. The silicon carbide layer is the main barrier to prevent the release of fission products and furthermore acts as a high-pressure vessel. These fuel elements retain most of the important fission products up to temperatures of $1000{ }^{\circ} \mathrm{C}$, which is the typical operating temperature of HTGR's currently in use [1]. Design studies for the International Generation IV Reactor Program consider HTGR's operating at temperatures significantly above $1000{ }^{\circ} \mathrm{C}$ to enhance their efficiency. As limited information on transport properties of fission products in silicon carbide above this temperature is available, our group started a few years ago a systematic study on the diffusion of environmentally relevant fission products in silicon carbide at temperatures above $1000{ }^{\circ} \mathrm{C}$. The results for strontium, silver, iodine and cesium [2-7] show that the formation of defect-impurity complexes plays an important role in the diffusion mechanism. However, the results for xenon diffusion [11] do not support such a mechanism. The current work investigates the transport of krypton in $6 \mathrm{H}-\mathrm{SiC}$ and CVD-SiC at temperatures up to $1400{ }^{\circ} \mathrm{C}$, to establish whether this is generally true for noble gases.

\section{Experiment and analysis}

Hexagonal 6H-SiC from Intrinsic Semiconductors ${ }^{\circledR}$ and CVD-SiC from Valley Design Corporation ${ }^{\circledR}$, having a columnar structure of mainly $3 \mathrm{C}$-SiC crystallites, were used in this study. Krypton ions were implanted at room temperature (RT), $350{ }^{\circ} \mathrm{C}$ and $600{ }^{\circ} \mathrm{C}$ with an energy of $360 \mathrm{keV}$ and a 
fluence of $2 \times 10^{16} \mathrm{~cm}^{-2}$. The flux was kept below $10^{13} \mathrm{~cm}^{-2} \mathrm{~s}^{-1}$ to prevent target heating. The different implantation parameters made it possible to compare transport processes in amorphous, poly and single crystalline silicon carbide. RBS-analysis before and after isochronal and isothermal vacuum annealing up to $1400{ }^{\circ} \mathrm{C}$ was employed to investigate transport properties of the implanted ions. In the case of single crystalline samples these measurements were combined with the results of $\alpha$-particle channeling spectroscopy along the c-direction to obtain defect density profiles as a function of implantation and annealing temperatures. Structural information on the samples before and after annealing was obtained by scanning electron microscopy (SEM). A detailed description of the experimental techniques is given elsewhere [4].

Diffusion coefficients were extracted from the broadening of implantation profiles during isothermal annealing. Assuming a Gaussian depth distribution the following relationship between the final and original widths holds [8]:

$[W(t)]^{2}=4 D t \ln (2)+[W(0)]^{2}$

$W(t)$ is the full width at half-maximum after annealing for time $t$. Hence, the diffusion coefficient $D$ at temperature $T_{a}$ is directly obtained from the slope of a plot of $[W(t)]^{2}$ versus annealing time $t$.

For the determination of defect density profiles, Rutherford backscattering spectra were measured for random and aligned incidence along the (0001)-direction (RBS/C), using $1.44 \mathrm{MeV}$ and 1.65 $\mathrm{MeV} \alpha$-particles. Irradiation damage in the $6 \mathrm{H}-\mathrm{SiC}$ samples consists of uncorrelated and correlated displaced atoms due to point defect clusters/amorphous regions and extended defects respectively. The computer code DICADA [9], which makes use of a modified master equation approach based on Lindhard's channeling theory, can obtain defect density profiles, provided that only uncorrelated displacements are present. However, a modified version of it, DICADA1 [10], can treat a mixture of uncorrelated point defects and dislocation loops, but is applicable only to mono-elementary targets. However, by introducing certain approximations it can be successfully applied to a binary target as shown and discussed in ref. [11]. A similar approach is also used in this work, assuming a Gaussian density distribution of dislocation loops with $z_{\max }=200 \mathrm{~nm}$ and $\sigma=40 \mathrm{~nm}$.

\section{Results and discussion}

RBS/C spectra and the computed defect density profiles for the as-implanted $6 \mathrm{H}-\mathrm{SiC}$ samples implanted at different temperatures $T_{i}$ are shown in Fig. 1. The cold implantation leads to an amorphous surface layer with a thickness of approximately $150 \mathrm{~nm}$, in which the krypton is fully embedded. During hot implantations the basic crystal structure is retained, although displaying a relatively large damage peak at $350{ }^{\circ} \mathrm{C}$ and a significantly smaller one at $600{ }^{\circ} \mathrm{C}$. In both hot implants the relative defect density in the surface region is low, although the density of dislocation loops compared to the RT implantation is about $11 \%$ higher in the $350{ }^{\circ} \mathrm{C}$ and $16 \%$ higher in the $600{ }^{\circ} \mathrm{C}$ implant. The difference in defect densities is due to a strong temperature dependence of irradiation induced annealing, which leads to increased point defect annihilation but also to a higher creation rate of extended defects. It also results in a broadening of the implantation profiles and higher krypton losses during hot implantations.

\subsection{Annealing of $6 \mathrm{H}-\mathrm{SiC}$}

The annealing behavior of the cold and hot implanted hexagonal samples differs fundamentally due to the completely different structure of the irradiation damage. SEM observations show that the amorphous region of the cold implant recrystallizes into a finely grained polycrystalline structure after a short annealing period at $900{ }^{\circ} \mathrm{C}$, which cannot be removed even after prolonged annealing 

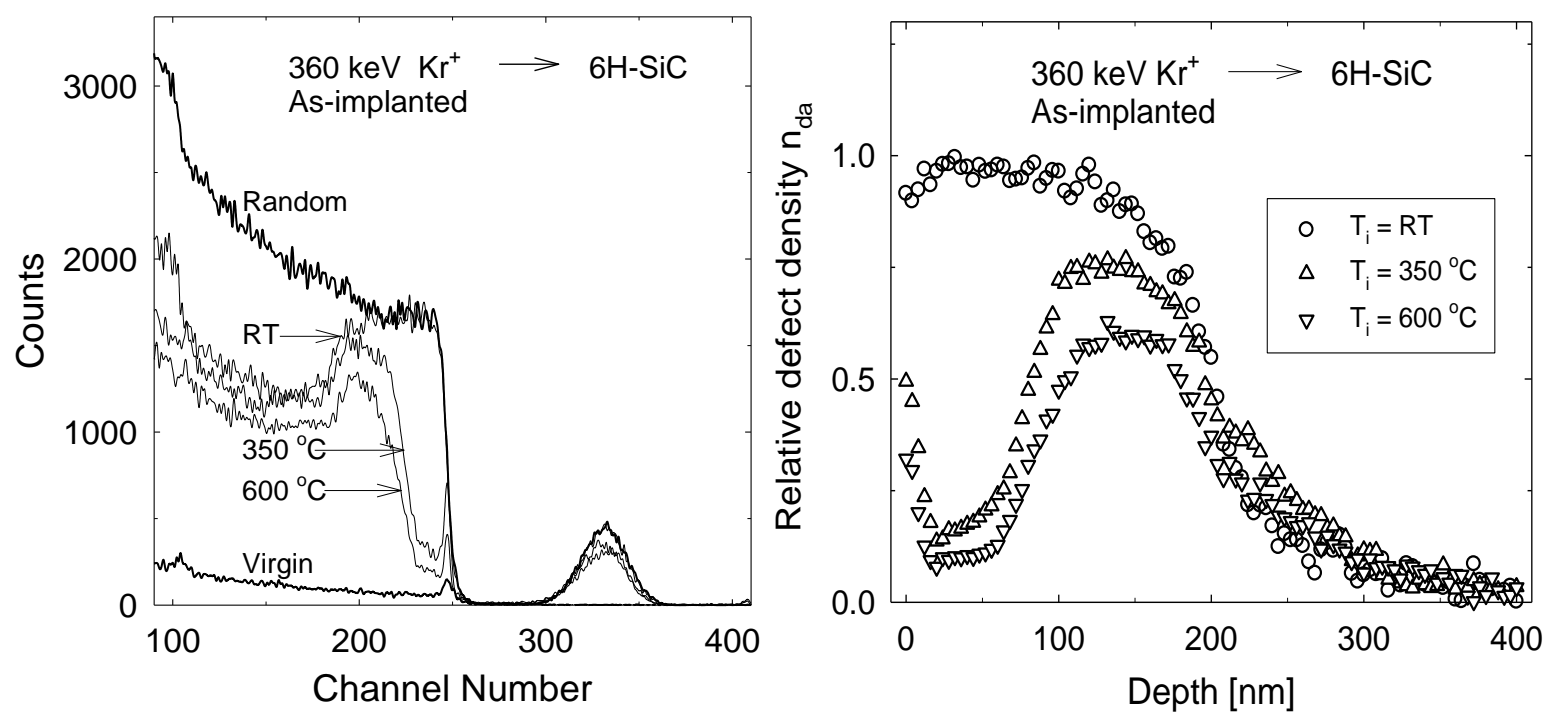

Fig. 1: RBS/C spectra and defect density profiles of $6 \mathrm{H}-\mathrm{SiC}$ implanted at different temperatures with a fluence of $2 \times 10^{16} \mathrm{Kr}^{+} \mathrm{cm}^{-2}$ at $360 \mathrm{keV}$.

at $1200{ }^{\circ} \mathrm{C}$. At higher temperatures the polycrystalline surface layer is removed by thermal etching, exposing the krypton implant. This process is clearly observed in Fig. 2, which shows that after isochronal annealing for 5 hours at $1400{ }^{\circ} \mathrm{C}$ the krypton profile moves to the surface, leading to the loss of approximately $25 \%$ of the implanted krypton. Fig 3 shows profile widths and retention of krypton during isochronal annealing for the different implantation temperatures. Both of these quantities stay constant during isochronal annealing of the cold implants up to $1100{ }^{\circ} \mathrm{C}$. At $1200{ }^{\circ} \mathrm{C}$ a small increase of the profile width is observed. That this is a real effect and not just a statistical fluctuation was proven by isothermal annealing at this temperature, showing further broadening with increasing time. Similar studies at $1100^{\circ} \mathrm{C}$ do not lead to significant changes of the krypton or defect profiles, while prolonged annealing at $1400{ }^{\circ} \mathrm{C}$ produces serious surface erosion after about 20 hours. Fig. 4 depicts defect density profiles after isothermal annealing at $1200{ }^{\circ} \mathrm{C}$ and $1300{ }^{\circ} \mathrm{C}$. During the initial annealing step at $1200{ }^{\circ} \mathrm{C}$ the original amorphous layer transforms into a somewhat thinner poly-crystalline layer due to epitaxial regrowth from the undamaged bulk. At $1300{ }^{\circ} \mathrm{C}$ the onset of surface deterioration becomes evident. Hence, the extreme broadening observed during isochronal annealing for 5 hours at $1400{ }^{\circ} \mathrm{C}$ is probably mainly due to a restructuring effect of the surface region and not to diffusion. Fig 5 is a SEM image after 20 hours annealing at $1400{ }^{\circ} \mathrm{C}$. Most of the original surface layer has been removed and large crystals have grown, modifying the surface morphology drastically. Before annealing the surface was absolutely featureless; this is always the case after RT implantation of heavy ions at high fluence due to amorphization of the surface region [7].

In contrast to the cold implants, the implantations at $350{ }^{\circ} \mathrm{C}$ and $600{ }^{\circ} \mathrm{C}$ retain their basic single crystalline structure, although relatively strong damage peaks are observed with maxima near the projected range of the krypton ions. The evolution of the defect profiles during isochronal annealing is shown in Fig. 6. Reduction of defect densities is only observed above $1000^{\circ} \mathrm{C}$. The significantly different annealing behavior seems to indicate, that the distribution of defect structures with different activation energies depends on the implantation temperature. However, from Fig. 3 it is quite clear that the damage reduction is not accompanied by any krypton transport. No krypton is lost and within experimental uncertainty its profile width does not change up to a temperature of $1400{ }^{\circ} \mathrm{C}$. 

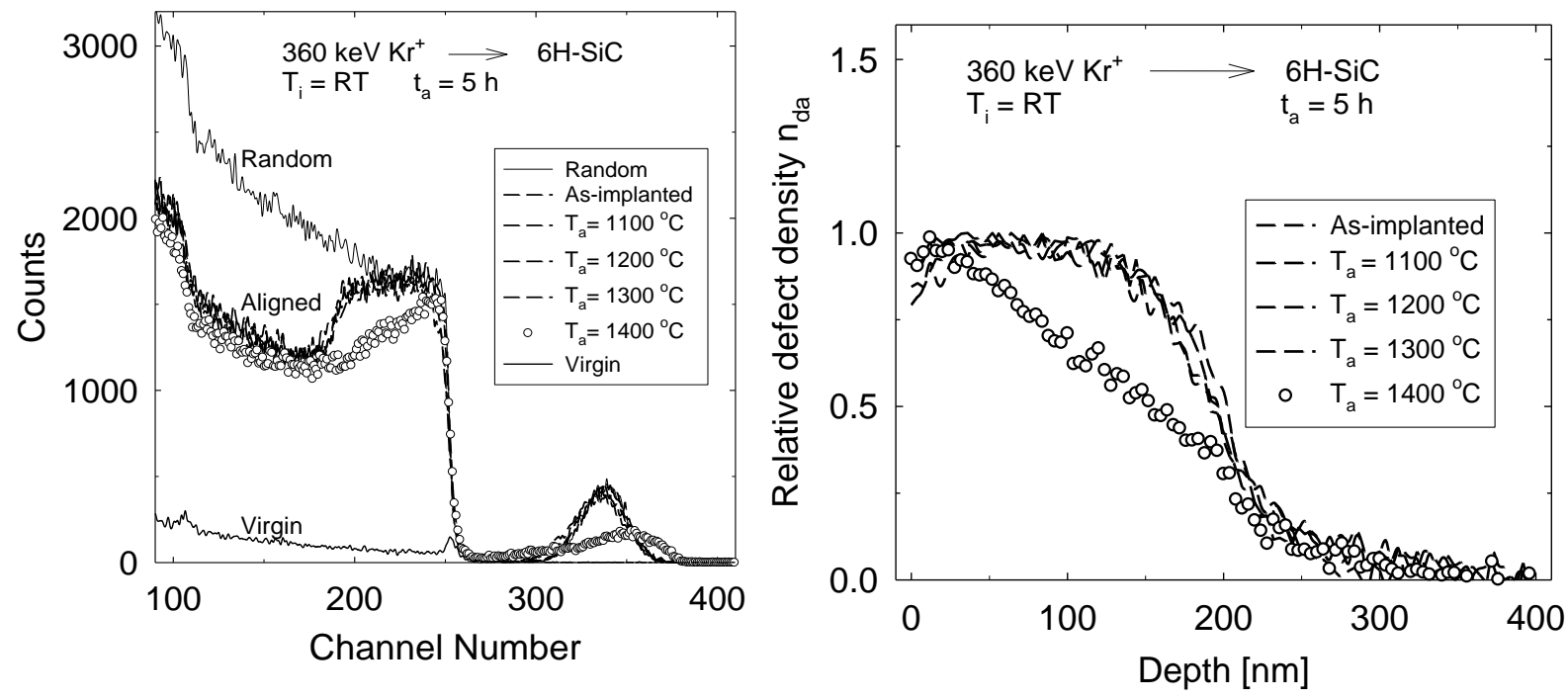

Fig. 2: $\mathrm{RBS} / \mathrm{C}$ spectra and defect density profiles of $6 \mathrm{H}-\mathrm{SiC}$ implanted at $\mathrm{RT}$ with a fluence of $2 \times 10^{16} \mathrm{Kr}^{+} \mathrm{cm}^{-}$ ${ }^{2}$ at $360 \mathrm{keV}$ before and after isochronal annealing.
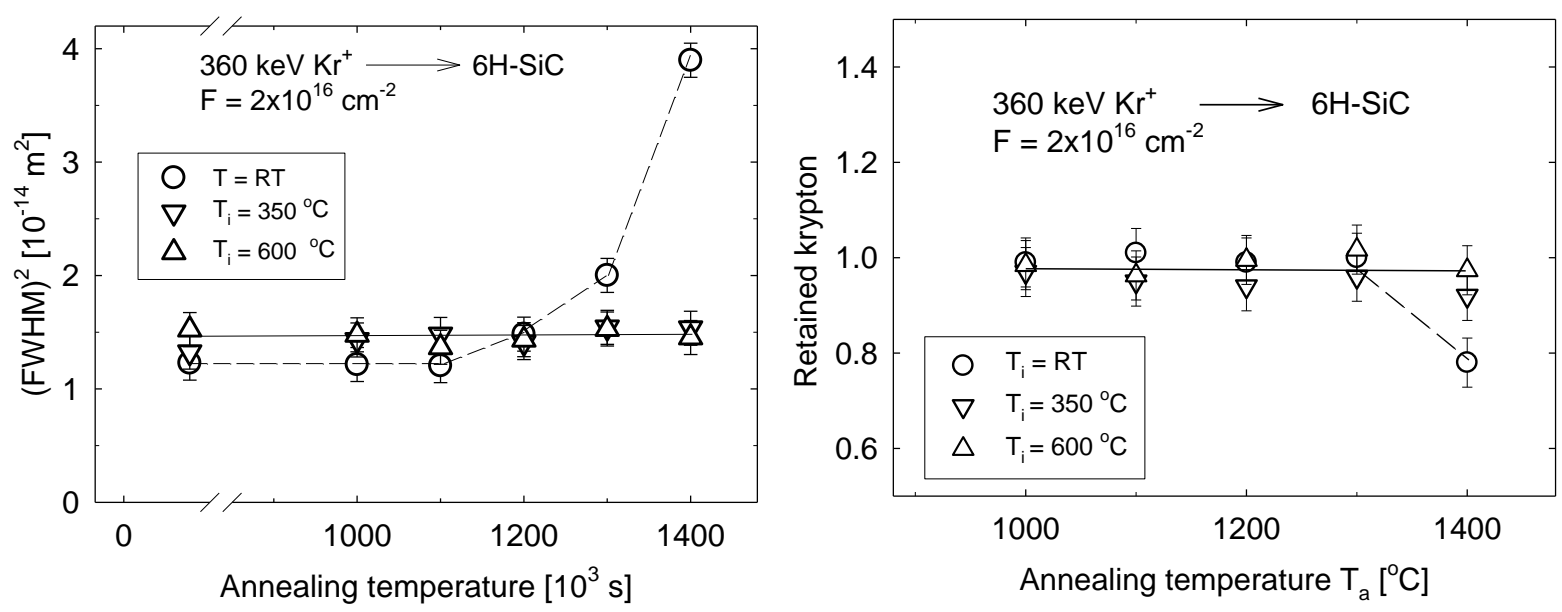

Fig. 3 Isochronal annealing curves of $6 \mathrm{H}-\mathrm{SiC}$ after implantation at different temperatures with a fluence of $2 \times 10^{16} \mathrm{Kr}^{+} \mathrm{cm}^{-2}$ at $360 \mathrm{keV}$. 

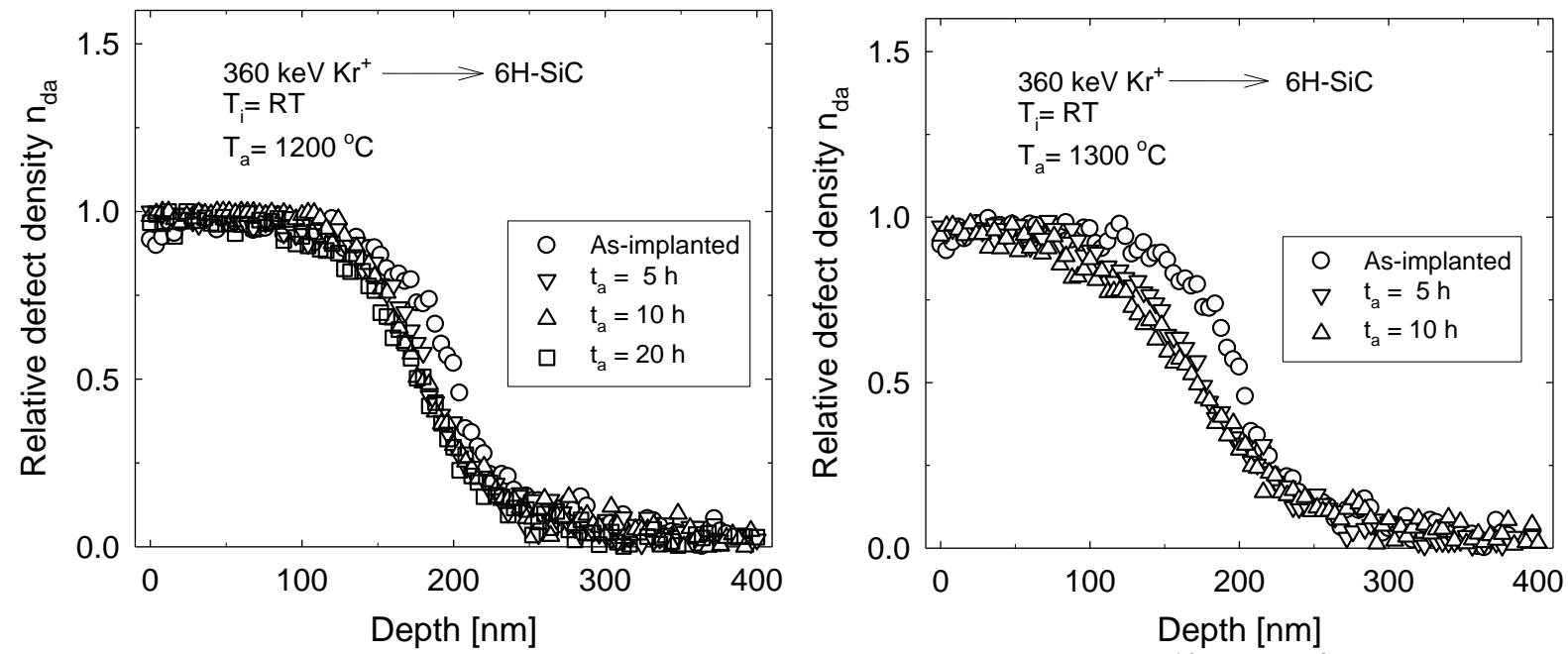

Fig. 4: Defect density profiles of $6 \mathrm{H}-\mathrm{SiC}$ implanted at $\mathrm{RT}$ with a fluence of $2 \times 10^{16} \mathrm{Kr}^{+} \mathrm{cm}^{-2}$ at $360 \mathrm{keV}$ before and after isothermal annealing.

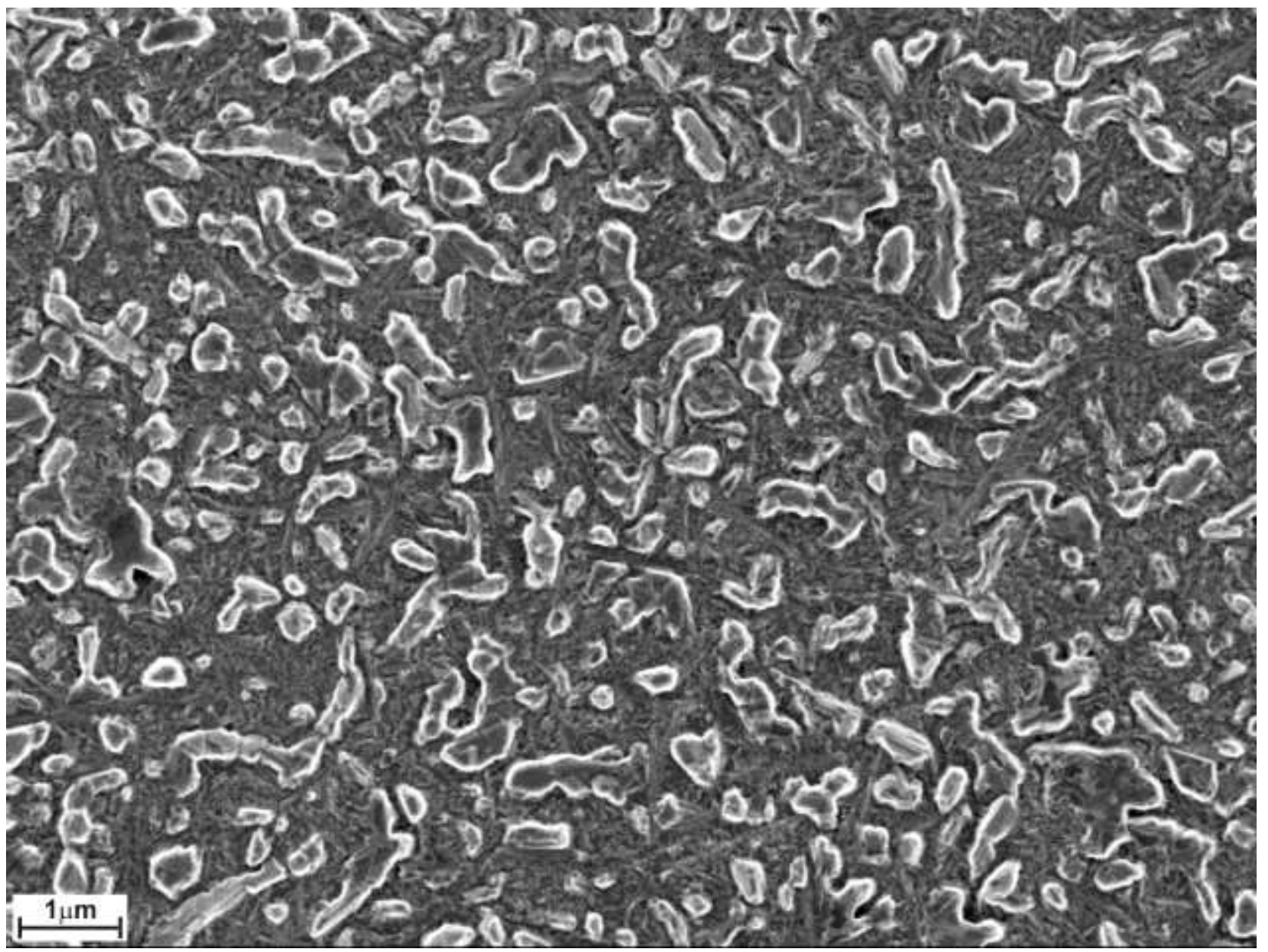

Fig. 5: SEM image of $6 \mathrm{H}-\mathrm{SiC}$ implanted at $\mathrm{RT}$ with a fluence of $2 \times 10^{16} \mathrm{Kr}^{+} \mathrm{cm}^{-2}$ at $360 \mathrm{keV}$ after annealing for 20 hours at $1400{ }^{\circ} \mathrm{C}$. 

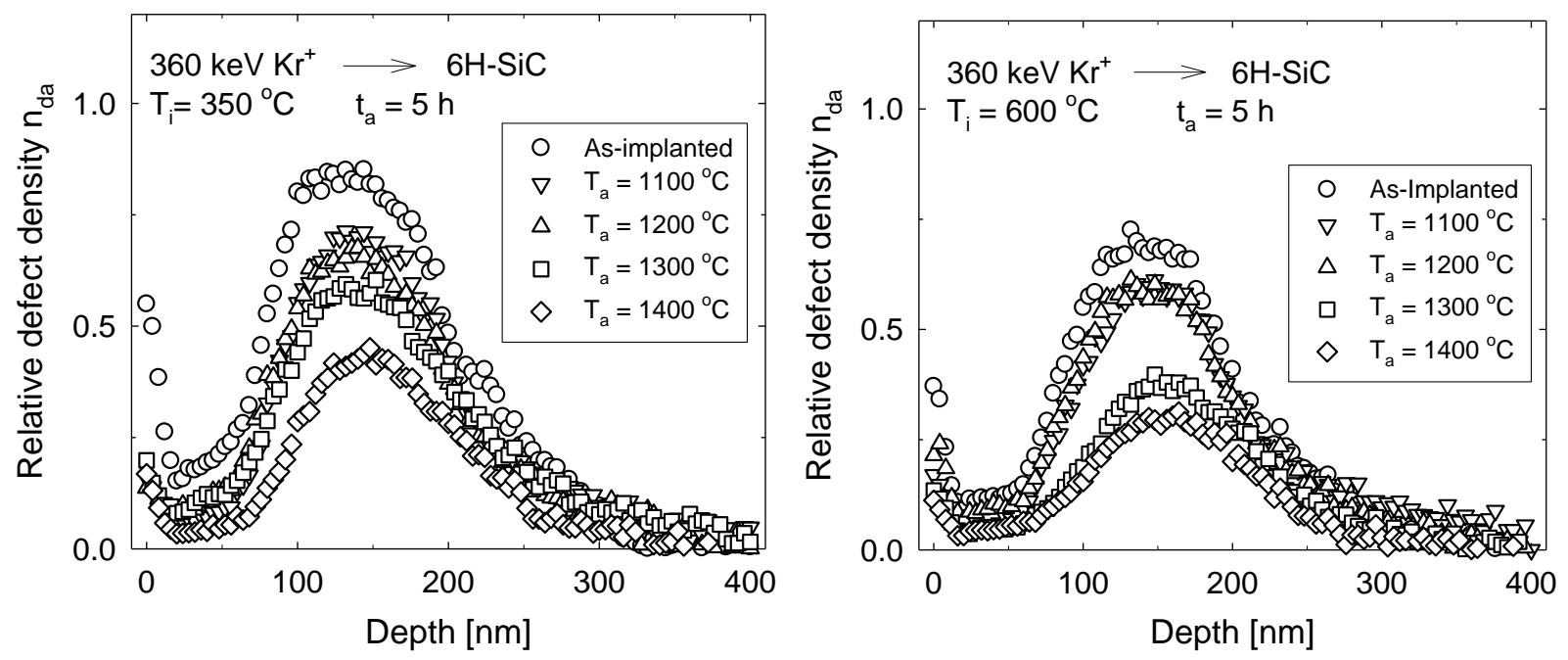

Fig. 6: Defect density profiles of $6 \mathrm{H}-\mathrm{SiC}$ implanted at $350{ }^{\circ} \mathrm{C}$ and $600{ }^{\circ} \mathrm{C}$ with a fluence of $2 \times 10^{16} \mathrm{Kr}^{+} \mathrm{cm}^{-2}$ at $360 \mathrm{keV}$ before and after isochronal annealing.

\subsection{Annealing of CVD-SiC}

Isothermal annealing curves at $\mathrm{T}_{\mathrm{a}}=1200{ }^{\circ} \mathrm{C}$ and $\mathrm{T}_{\mathrm{a}}=1300{ }^{\circ} \mathrm{C}$ for CVD-SiC implanted at $\mathrm{RT}$ are shown in Fig. 7. No krypton transport is observed at $1100^{\circ} \mathrm{C}$, which means that the diffusion coefficient at this temperature is below our detection limit of about $10^{-21} \mathrm{~m}^{2} \mathrm{~s}^{-1}$. However, at $1200{ }^{\circ} \mathrm{C}$ the profile width increases linearly with annealing time. From its slope a diffusion coefficient of $6 \times 10^{-20} \mathrm{~m}^{2} \mathrm{~s}^{-1}$ is obtained at $1200{ }^{\circ} \mathrm{C}$. At $1300{ }^{\circ} \mathrm{C}$ surface deterioration makes any analysis meaningless. No krypton loss is observed at both annealing temperatures after 20 hours.

Fig. 8 depicts annealing curves at $1200^{\circ} \mathrm{C}$ and $1300{ }^{\circ} \mathrm{C}$ for an implantation temperature of $350{ }^{\circ} \mathrm{C}$. For these temperatures the diffusion coefficients determined from the slopes are $1 \times 10^{-20} \mathrm{~m}^{2} \mathrm{~s}^{-1}$ and $4 \times 10^{-20} \mathrm{~m}^{2} \mathrm{~s}^{-1}$ respectively, while again no diffusion is observed at $1100^{\circ} \mathrm{C}$. Within experimental uncertainty no krypton loss is observed after 20 hours at any of the annealing temperatures. As no diffusion up to $1400{ }^{\circ} \mathrm{C}$ was observed for the $6 \mathrm{H}-\mathrm{SiC}$, the diffusion of krypton in CVD-SiC must be due to grain boundary diffusion.
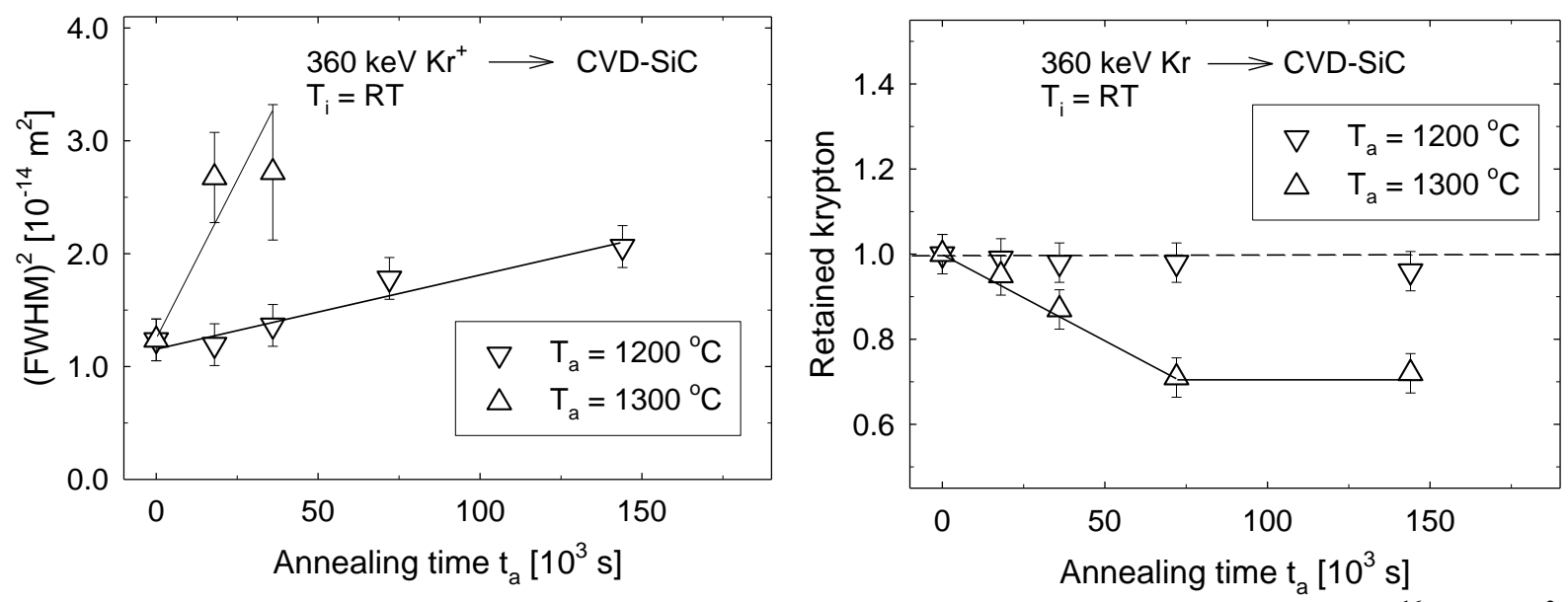

Fig. 7: Isothermal annealing curves of CVD-SiC after implantation at $\mathrm{RT}$ with a fluence of $2 \times 10^{16} \mathrm{Kr}^{+} \mathrm{cm}^{-2}$ at $360 \mathrm{keV}$. 

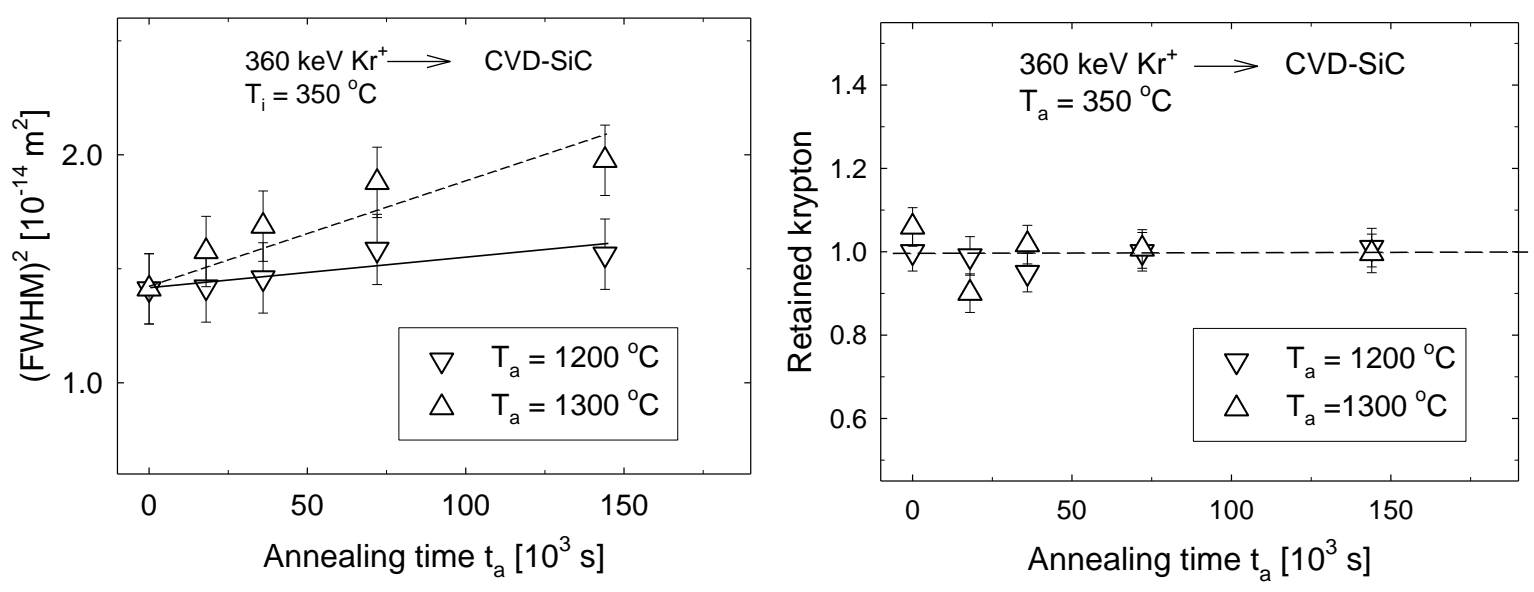

Fig. 8: Isothermal annealing curves of CVD-SiC after implantation at $350{ }^{\circ} \mathrm{C}$ with a fluence of $2 \times 10^{16} \mathrm{Kr}^{+}$ $\mathrm{cm}^{-2}$ at $360 \mathrm{keV}$.

\section{Conclusion}

In $6 \mathrm{H}-\mathrm{SiC}$ the krypton losses during high temperature implantations due to irradiation induced diffusion are relatively low compared with those observed for the xenon implantations [11]. At 350 ${ }^{\circ} \mathrm{C}$ and $600{ }^{\circ} \mathrm{C}$ the losses are only $6 \%$ and $10 \%$ respectively compared with the implantation at RT. This is at least three times less than with xenon ions. However, similarly as the xenon results, no losses are observed during isochronal or isothermal annealing up to $1200{ }^{\circ} \mathrm{C}$ in cold and up to 1400 ${ }^{\circ} \mathrm{C}$ in hot implants. At higher temperatures the occurrence of serious surface erosion made measurements unreliable.

During the initial annealing stage, when the krypton is still embedded in either amorphous or highly damaged crystalline matter, no diffusion is detectable. This was also the case for the xenon implants, but in disagreement with all the other diffusors studied so far, where such initial diffusion was generally observed [7] and was explained by a release and capture mechanism of defectimpurity complexes. A plausible explanation of this difference is that the chemically inert noble gases do not form defect complexes, but rather segregate into immobile planar clusters with an epitaxial alignment in the hexagonal crystal structure of the substrate.

In CVD-SiC diffusion occurs along grain boundaries, which are known to be sinks for defects and their structure and diffusion properties should therefore depend strongly on the irradiation damage incurred during implantation. The sample amorphized during RT-implantation shows no measurable diffusion at $1100{ }^{\circ} \mathrm{C}$ but relatively strong diffusion occurs at $1200{ }^{\circ} \mathrm{C}$. At $1300{ }^{\circ} \mathrm{C}$ extreme profile broadening is observed which probably is mainly due to surface erosion. SEM investigations show that the original grain structure is preserved, although additionally a finely grained structure within the individual crystallites is present. This opens additional diffusion paths, which explain the significantly higher diffusion coefficient found for the RT implant compared with the value obtained for the target implanted at $350^{\circ} \mathrm{C}$. It is also the reason for the much stronger thermal etching effect, as the additional grain structure decreases the binding energy of the surface atoms.

No krypton loss is observed in the hot implanted target during annealing at $1300{ }^{\circ} \mathrm{C}$ for up to 40 hours. However, the target implanted at RT loses at this temperature about $30 \%$ of the krypton after 20 hours but nothing further during the next 20 hours. A similar phenomenon was also observed for the xenon implantation at RT, when 50\% was lost after 10 hours annealing at $1300{ }^{\circ} \mathrm{C}$ and no further loss during the next 30 hours. The lost fraction was most likely situated in or near the original and newly formed grain boundaries, while out-diffusion of krypton from deep inside these crystal- 
lites does not occur. The apparently large contribution of the newly formed grain boundaries is surprising, as it would be expected, that their high degree of tortuosity should have hindered effective out-diffusion $[12,13]$.

\section{Acknowledgements}

Financial support of the National Research Foundation is gratefully acknowledged. Thanks are due to Elke Wendler, who arranged the implantations by the ion beam group of the Institut für Festkörperphysik in Jena.

\section{References}

[1] D. Hanson, A Review of Radionuclide Release from HTGR Cores During Normal Operation, Electric Power Research Institute, Report 1009382, March 2004.

[2] E. Friedland, J.B. Malherbe, N.G. van der Berg, T. Hlatshwayo, A.J. Botha, E. Wendler, W. Wesch, J. Nucl. Mater. 389, 326 (2009).

[3] E. Friedland, N.G. van der Berg, J.B. Malherbe, R.J. Kuhudzai, A.J. Botha, E. Wendler, W. Wesch, Nucl. Instr. and Meth. B 268, 2892 (2010).

[4] E. Friedland, N.G. van der Berg, J.B. Malherbe, J.J. Hanke, J. Barry, E. Wendler, W. Wesch, J. Nucl. Mater. 410, 24 (2011).

[5] E. Friedland, N.G. van der Berg, J.B. Malherbe, E. Wendler,. W. Wesch, J. Nucl. Mater. 425, 205 (2012).

[6] E. Friedland, N.G. van der Berg, T.T. Hlatshwayo, R.J. Kuhudzai, J.B. Malherbe, E. Wendler, W. Wesch, Nucl. Instr. and Meth. B 286, 102 (2012).

[7] E. Friedland, T.T. Hlatshwayo, N.G. van der Berg, Phys. Stat. Solidi C 10, 208 (2013).

[8] S.M. Myers, S.T. Picraux, T.S. Prevender, Phys. Rev. B 9, 3953 (1974).

[9] K. Gärtner, Nucl. Instr. and Meth. B 227, 522 (2005).

[10] K. Gärtner, A. Ugguzoni, Nucl. Instr. and Meth. B 67, 189 (1992).

[11] E. Friedland, K. Gärtner, T.T. Hlatshwayo, N.G. van der Berg, T.T. Thabethe, Nucl. Instr. and Meth. B 332, 415 (2014).

[12] D.A. Petti, J. Buongiorno, J.T. Maki, R.R. Hobbins, G.K. Miller, Nucl. Eng. 222, 281 (2003).

[13] R. Kirchhofer, J.D. Hunn, P.A. Demkowicz, J.I. Cole, B.P. Gorman, J. Nucl. Mater. 432, 127 (2013). 